\title{
Der 2. Jahresempfang der Buchpatinnen und Buchpaten 2017
}

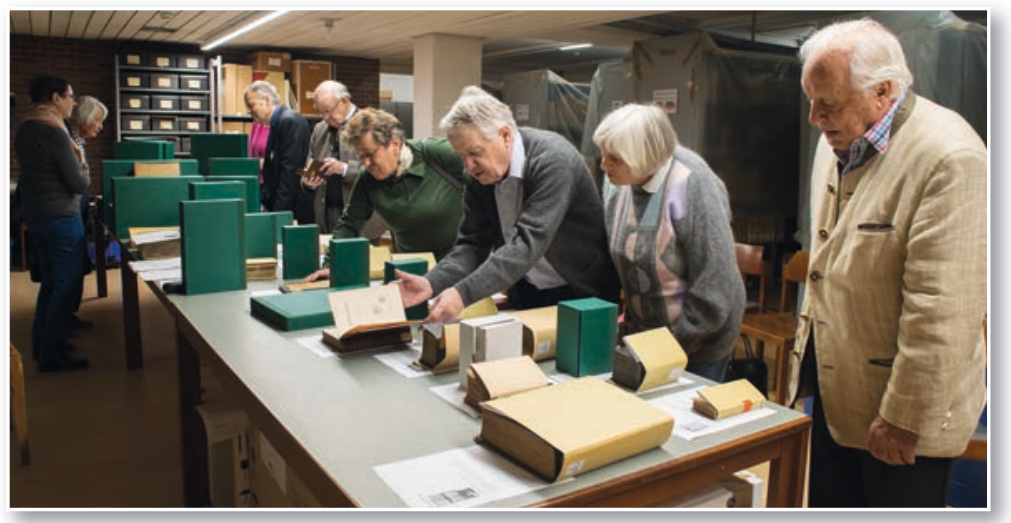

An einem trüben Freitagnachmittag im November 2017 sah man im Handschriftenmagazin der Bibliothek bei zehn bibliophilen Buchpaten und -patinnen die Sonne aufgehen. Der Leiter der Historischen Sammlungen, Herr Dr. Christian Herrmann, referierte über die restaurierten Objekte, die sich die Buchpaten selbst aus einer Liste stark beschädigter Bücher ausgewählt hatten, stellte die Werke in ihre jeweiligen historisch-theologischen Bezüge und beantwortete sämtliche Fragen der interessierten Runde. Die Stücke, die sich vor der Behandlung durch externe Restauratoren in einem desolaten Zustand befunden hatten, präsentierten sich nun mit gestärktem Rücken, geschlossenen Rissen, stabilisierten Seiten oder nachgehefteten Lagen.

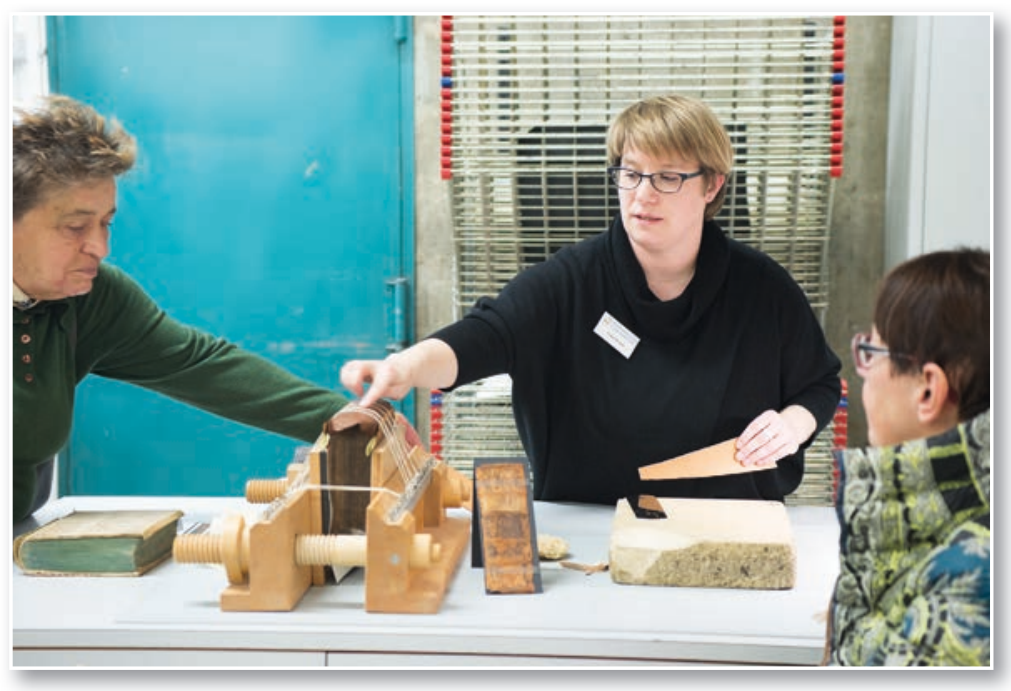

Zu sehen waren z. B. eine "Humanistenbibel" von 1551, eine "Illustrierte Pferdekunde" von 1734 oder eine "Orientalische Liebeslyrik" aus dem Jahr 1854.

Parallel dazu führten die Restauratorin Frau Sonja Brandt und die für die Bestandserhaltung zuständige Referentin, Frau Dr. Ida Danciu, die zweite Gruppe der Buchpaten durch die renovierte Restaurierungswerkstatt. Anhand verschiedener $\mathrm{Pa}$ piere und Materialien erläuterten sie unterschiedliche Restaurierungstechniken, Reinigungsarten, Stabilisierungsmethoden und Möglichkeiten der Papierergänzung. Sie wiesen auch auf die wichtigen präventiven Konservierungsmaßnahmen wie Verpackung, Lagerung oder Buchstützen hin und gaben hilfreiche Tipps für den privaten Umgang mit fragilen Buchmaterialien und Einbänden.

Mit anregenden Gesprächen und einem Gläschen Sekt klang der bibliophile Nachmittag in einer entspannten Atmosphäre aus.

Ausführlichere Informationen zum Buchpatenschaftsprogramm der WLB sowie eine Auswahl restaurierungswürdiger Bände finden Sie auf unserer Homepage:

http://www.wlb-stuttgart.de/die-wlb/freunde-derbibliothek/buchpatenschaften/

Martina Lüll 